\title{
Influence of Wire-tool Speed on Kerf Quality in Wire-EDM 304 Strainless Steel
}

\author{
Quanli $\operatorname{Han}^{1, a}$ and Hongqiang Wan ${ }^{1, b}$ \\ ${ }^{1}$ School of Mechanical \& Electrical Engineering, Xi'an Technological University, P. R. China \\ ahanqljx@163.com, b413162931@qq.com
}

Keywords: Wire-EDM; Kerf quality; Wire-tool speed

\begin{abstract}
This paper conducted slot-cutting of wire-EDM 304 stainless steel to investigate the effect of wire-tool speed on kerf quality. The special trajectory of wire-electrode was designed like the letter $\mathrm{L}$, and the width of kerf at the five points in one group was measured with optical image measuring instrument tin experiments. The experiments results showed that the wire-electrode speed of $0.10 \mathrm{~m} / \mathrm{s}$ can generate the optimal kerf quality on the whole length of slot, and the width difference along the kerf is not ignored expect the wire-electrode speed of $0.10 \mathrm{~m} / \mathrm{s}$. the conclusions can help to simplify the determination of processing parameters in WEDM application when required precision surface quality of product.
\end{abstract}

\section{Introduction}

Today's wire electrical discharge machining (Wire-EDM) is increasingly playing more important role in modern manufacturing industry, which attributes to its high-performance of machining and the ability to machine varying hardness materials or complex shapes. The most promising features of WEDM are related to geometrical accuracy, which reflected mainly on kerf quality. The kerf is resulted from materials removal from raw block, whose width is the cutting width in the work piece during machining. And the kerf width has a significant contribution to materials removal rate in terms of machining rate. In order to increase the machining rate in rough maching and processing quality in finish machining, researchers have been finding the methods to effectively control kerf, unfortunately, which is achieved difficultly owing to complexities of WEDM.

Since the generation of wire bending and vibration phenomena in the discharge gap, as well as their adverse impact, even skilled operators with the state-of-the-art of WEDM do difficultly success in effectively control kerf quality. Generally speaking, Kerf quality depends on wire trajectory error and wire bow error. Some curve fitting methods were used to describe the wire trajectory and several theory methods were applied to resolute the wire bow error and its resolution implemented practical measures [1-4]. The both error above mainly resulted from the wire defection and wire vibration, so Sarkar and Mingqi presented analytical model and experimental method to calculate wire deflection, and determine wire lag compensation strategy to enhance the precision of cylinder work piece [5, 6]. Fundamental geometry properties of corner-cutting were analyzed by derivation of corner error, and a few of ameliorative measures of corner error were used in actual machining process [1, 7-9]. Mohri investigate the mechanism of wire vibration and gave a mathematical model under single spark discharge and the $3^{\text {rd }}$ system equation to resolute the mathematical model considering material removal and vibration characteristics [10] Puri presented analytical method to solve the two-dimensional vibration equation of wire-tool in multiple spark discharges, and the relationship between the amplitude of wire vibration and the machining conditions was revealed from the solution of the equation [9]. Di gave a mathematical model of wire lateral vibration and derived its theoretical solution in micro-WEDM [11]. Tomura worked out two-dimensional distributions of current density and magnetic flux density and expound the impact electromagnetic force on wire vibration [12]. Murphy investigated the effect of temperature distribution on the wire vibration and developed a coupling structural-thermal model to describe the vibration and stability characteristics of wire-electrode [13]. However, in the actual discharge machining, kerf quality has focused on control 
the width in machining, but the knowledge and technology in field is still deficient enough to unable to meet the demand of industry. The main aim of the current research is to carry out an experimental investigate the influence of wire-electrode speed on kerf quality.

\section{Experiment}

304L strain less stain in 2mm thickness was chosen as work piece in WEDM, whose properties was listed in Table 1. And the WEDM machine was FA120 made by Mitsubishi with the ionized water as dielectric fluid and $20 \mu \mathrm{m}$ diameter wire used. The special design of wire-electrode trajectory was combined the subparts whose shape like letter L, in which, the radium of corner was theoretically $0.3 \mathrm{~mm}$ and the length of lines was $5 \mathrm{~mm}$ and $8 \mathrm{~mm}$ respectively, which was seen in Fig.1. The process was chosen in one cut, and the speed was two kinds, that is to say, slow and fast, whose value was gotten from the built-in system in WEDM machine used in the rough cutting and the finishing cutting, which was listed in Table 2. The five points in one subpart shaped like $\mathrm{L}$ were chosen as one group to measure the kerf width for given processing condition shown in Fig1 and are named as $\mathrm{Pi}$ ( $\mathrm{i}$ is equal to $1,2,3,4,5$ respectively), the amount of group is four so the total points is the product of 5 and 4 . Optical image measuring instrument (SVM-2515II, made in China) was used to got kerf width. The values of different groups with same index name were averaged to avoid of measurement error.

Table 1 Preperties of workpiece 304L

\begin{tabular}{|c|c|c|c|c|c|c|c|c|}
\hline \multicolumn{9}{|c|}{ Chemical component (percentage) } \\
\hline $\begin{array}{c}\mathrm{C} \\
0.07 \\
\end{array}$ & $\begin{array}{c}\mathrm{Si} \\
0.93 \\
\end{array}$ & & & $\begin{array}{c}\mathrm{Cr} \\
19.7 \\
\end{array}$ & $\begin{array}{l}\mathrm{Ni} \\
9.6 \\
\end{array}$ & $\begin{array}{c}S \\
0.02 \\
\end{array}$ & $\begin{array}{c}\mathrm{P} \\
0.03 \\
\end{array}$ & $\begin{array}{c}\mathrm{N} \\
0.09 \\
\end{array}$ \\
\hline \multicolumn{9}{|c|}{ Physical property } \\
\hline $\begin{array}{l}\text { Density } \\
\mathrm{g} / \mathrm{cm}^{3}\end{array}$ & \multicolumn{2}{|c|}{$\begin{array}{c}\text { Tensile } \\
\text { strength } \\
\text { (Mpa) }\end{array}$} & \multicolumn{2}{|c|}{$\begin{array}{c}\text { Yield } \\
\text { strength } \\
(\mathrm{Mpa})\end{array}$} & $\begin{array}{c}\text { Elongation } \\
(\%)\end{array}$ & \multicolumn{2}{|c|}{$\begin{array}{c}\text { HRB } \\
\text { Hardness }\end{array}$} & $\begin{array}{c}\text { HB } \\
\text { Hardness }\end{array}$ \\
\hline 7.93 & \multicolumn{2}{|c|}{520} & \multicolumn{2}{|c|}{207} & 40 & \multicolumn{2}{|c|}{90} & 187 \\
\hline
\end{tabular}

Table 2 Process parameters in WEDM experiment

\begin{tabular}{|c|c|c|c|}
\hline $\mathrm{t}_{\mathrm{on}}(\mu \mathrm{s})$ & $\mathrm{t}_{\text {off }}(\mu \mathrm{s})$ & $\mathrm{U}(\mathrm{V})$ & $\mathrm{v}(\mathrm{m} / \mathrm{s})$ \\
\cline { 1 - 3 } 14.0 & 14.0 & 50.0 & \multirow{2}{*}{$0.15,0.10,0.08$} \\
\cline { 1 - 3 } 8.0 & 8.0 & 30 & \\
\hline
\end{tabular}

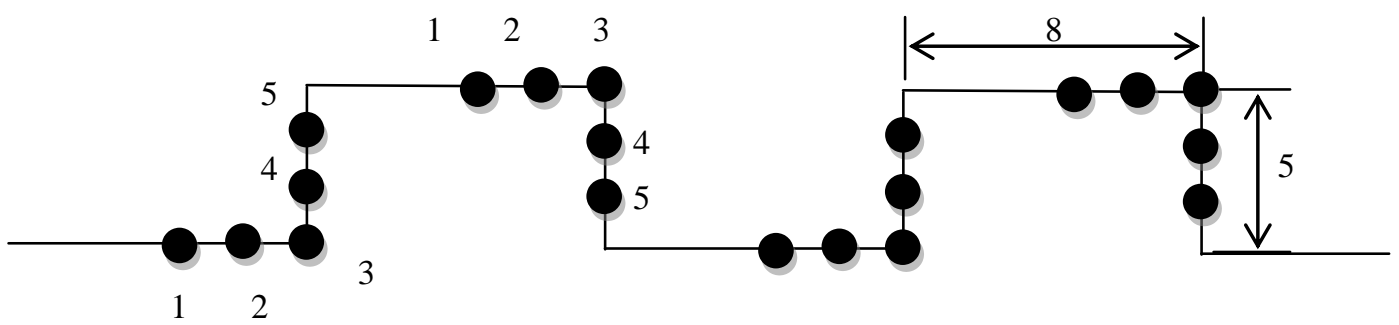

Figure 1. Wire trajectory designed in experiment 


\section{Result and discussion}

Fig. 2 shows measurement result of kerf width in WEDM. From Fig. 2 the almost similar trend of kerf width is obviously seen. The maximum of kerf width is gotten at the point of the corner in each experiment, and the kerf width in different point is not constant on the way of slot, that is, width error is seen.

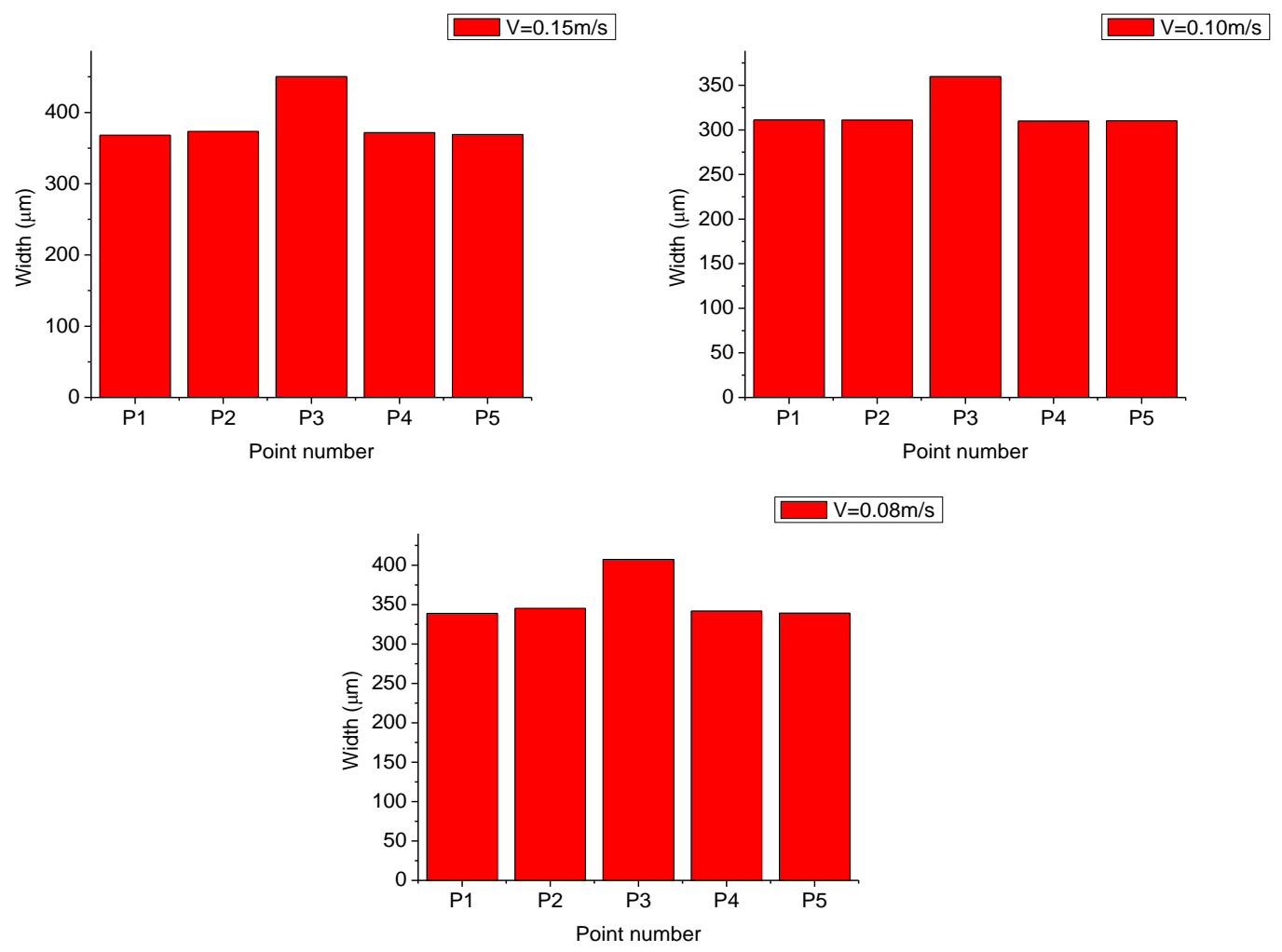

Figure 2. Measurement result of kerf width in experiments

The kerf width $(\mathrm{w})$ consists in the following parts, that is, the wire radius, the breakdown distance $\left(\mathrm{d}_{0}\right)$, and the amplitude of lateral vibration $\left(\mathrm{u}_{\max }\right)$, which is seen in Fig.3. The amplitude of lateral vibration can be obtained from $\mathrm{d}_{0}$ and $\mathrm{w}$, while the breakdown distance depends on the discharge voltage (U) and the insulation medium, which value is gotten in the way like the reference [14].

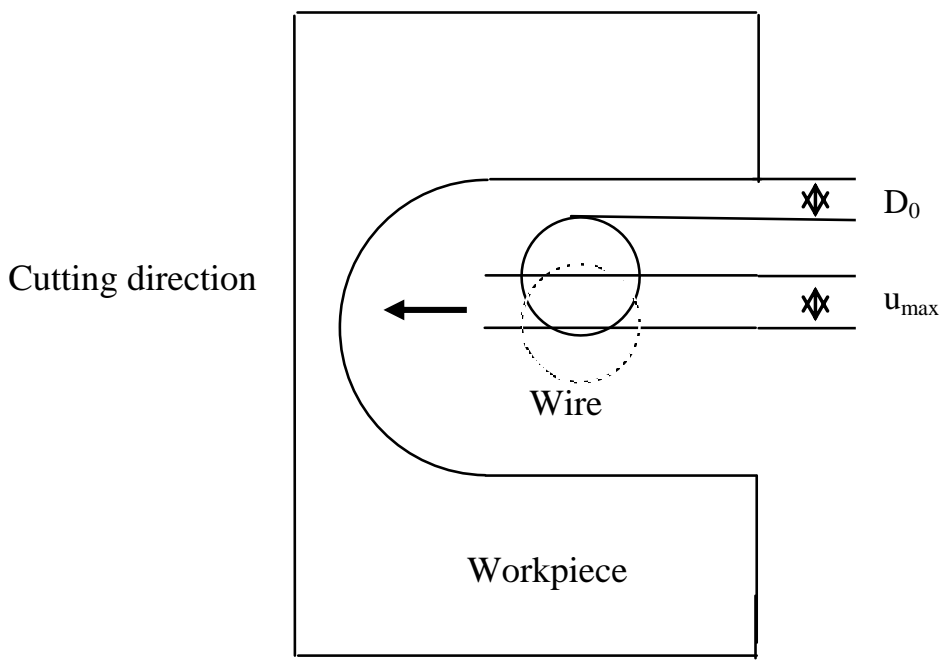

Figure 3. Finite element calculation model of arch dam and bedrock 
To investigate the effect of wire-electrode speed on kerf quality in WEDM, the relationship between the kerf width and the speed is taken out, which is seen in Fig.4. Fig 4 tells us that the optimal quality of kerf is gotten at the middle speed, that is to say, whose value is $0.10 \mathrm{~m} / \mathrm{s}$. and the range of kerf width in different points is the narrowest, which means the better quality of kerf. The reason to this is related to the effect of the speed, the magnitude of amplitude of lateral vibration at this speed is the minimum. Moreover, the change of breakdown distance more less than the lateral vibration in given condition, and even through the breakdown distance increase with the discharge voltage. The combined effect of $\mathrm{d}_{0}$ and $\mathrm{u}_{\max }$ results in the final result.

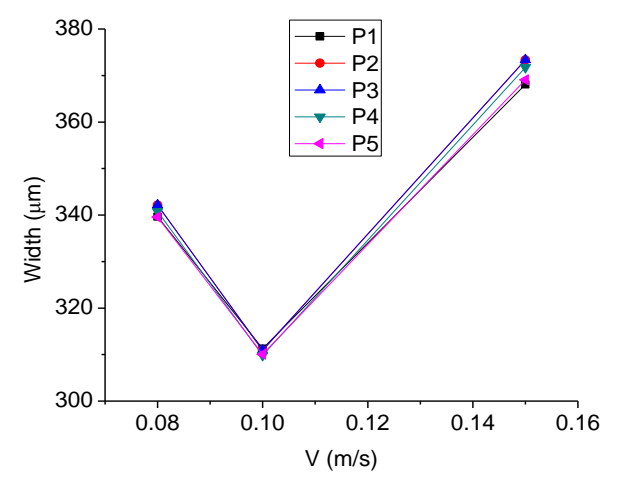

Figure 4. The relationship between the kerf width and the speed

At the others speed expect the value of $0.10 \mathrm{~m} / \mathrm{s}$, the width difference between varying points is not left out, and magnitude of difference in higher voltage is greater that in lower one. The reason for result above can be attributed to the increase in the volume of material removal, which generates with the help from the higher discharge voltage and the longer discharge time $\mathrm{T}_{\mathrm{on}}$.

\section{Conclusions}

This study has conducted the experiment to investigate the effect of wire-electrode speed on kerf quality in WEDM, and the following conclusions can be drawn:

(1) The wire-electrode speed of $0.10 \mathrm{~m} / \mathrm{s}$ can generate the optimal kerf quality, because the amplitude of lateral vibration at this speed is the minimum.

(2) Expect the wire-electrode speed of $0.10 \mathrm{~m} / \mathrm{s}$, the width difference along the kerf is not ignored, and magnitude of difference in higher voltage is greater that in lower one, which attributes to the volume change of material removal

The future work, the database for different engineering materials in optimal kerf quality will be built, so it can be used to simplify the determination of processing parameters in WEDM application.

\section{Acknowledgements}

The author expresses great gratitude to the Doctor. Li from optical measurement laboratory photoelectric engineering college Xian technological university for help with the kerf width measurement. And the author wishes to acknowledge the support from the fund of Shaanxi key laboratory research project (16JS04).

\section{References}

[1] W. J.Hsue, Y.S. Liao, S.S. Liu, Fundamental geometry analysis of wire electrical discharge machining in corner cutting, J. Mach. Tools Manuf. 39(1999) 651-667

[2] A. B. Puri, B. Bhattacharyya, An analysis and optimization of the geometrical inaccuracy due to wire lag phenomenon in WEDM, J. Mach. Tools Manuf. 43(2003) 151-159 
[3] Y. F. Luo, Rupture failure and mechanical strength of the electrode wire used in wire EDM, J. Mater. Process. Technol. 94(1999) 208-215

[4] G. Zhang, Z. Chen, Z. Zhang, Y. Huang, H. Li, A macroscopic mechanical model of wire electrode deflection considering temperature increment in MS-WEDM process, J. Mach. Tools Manuf. 78(2014) 41-53

[5] M. Q. Li, M. H. Li, G.Y. Xi, Study on the variations of form and position of the wire electrode in WEDM - HS, J. Adv. Manuf. Technol. 25(2005) 929-934

[6] S. Sarkar, M. Selch, S. Mitra, B. Bbhattacharyya, A novel method of determination of wire lag for enhanced profile accuracy in WEDM, Precis. Eng. 35(2001)339-347

[7] J. A. Sanchz, J. L. Rodil, Corner error simulation of rough cutting in wir EDM, Precis. Eng. 182(2007)331-336

[8] [8Z. Che, Y. Huang, Z. Zhang, H. Li, W. Ming, G. Zhang. An analysis and optimization of the geometrical inaccuracy in WEDM rough corner cutting, J. Adv. Manuf. Technol. 74(2014) 917-929

[9] F. Han, J. Zhang, I. Soichiro, Corner error simulation of rough cutting in wire WDM, Precis. Eng. 31(2007)331-336

[10] J. van der Geer, J.A.J. Hanraads, R.A. Lupton, The art of writing a scientific article, J. Sci. Commun. 163 (2000) 51-59.

[11]F. W. J. Hsue, D.Di, X.Chu.D.Wei.Z.Wang. G.Chi, Y.Liu. Aanalysis of kerf width in micro-WEDM, J.Mach.Tools Manuf. 49(2009) 788-792

[12] S. Tomura, M. Kunieda, Analysis of electromagnetic force in wire-EDM, Precis. Eng. 33(2009) 225-262

[13] K. D. Murply, Z. Liu, The influence of spatially non-uniform temperature fields on the vibration and stability characteristics of EDM wires, J. Mech. Sci. 42(2000)1369-1390

[14]Z. Chen, Y. Huang, H. Huang, Zh. Zhang, G. J. Zhang, J. Zhang, Three-dimensional characteristics analysis of the wire-tool vibration considering spatial temperature field and electromagnetic field in WEDM. J. Mach. Tools Manuf. 92(2015) 85-96 